\title{
An Ultrasensitive Immunoassay Strip for Simultaneously Detecting Cyproheptadinehydrochloride and Six Phenothiazinesin Feedstuffs Based on a Monoclonal Antibody
}

\section{Guanqiong $\mathrm{Na}$}

Henan Academy of Agricultural Sciences

Xiaofei Hu

Henan Academy of Agricultural Sciences

\section{Yaning Sun}

Henan Academy of Agricultural Sciences

Liang Tang

University of Texas at San Antonio

Guangxu Xing

Henan Academy of Agricultural Sciences

\section{Yunrui Xing}

Henan Academy of Agricultural Sciences

Gaiping Zhang ( $\sim$ zhanggaip@126.com )

Jiangnan University

\section{Research}

Keywords: Monoclonal antibody, Cyproheptadine, Phenothiazines, Immunochromatographic strip, Rapid detection

Posted Date: June 1st, 2020

DOI: https://doi.org/10.21203/rs.3.rs-31729/v1

License: (c) (i) This work is licensed under a Creative Commons Attribution 4.0 International License.

Read Full License 


\section{Abstract}

Background: An antihistamine cyproheptadine (CPH) and phenothiazines (PZs)sedative hypnoticshave a similar tricyclic structure, these drugs are often illegally added to food animal feedstuffs due to their price advantage and significant effect in promoting growth and improving meat quality. However, the abuse of these drugs may lead totheir residues in animal products, thereby causing harmful effects such as allergies and dermatological reactions on human health.To supervise the use of prohibited drugs and ensure food safety, it is necessary to establish a simple and effective screening method to detect $\mathrm{CPH}$ and PZs.In this research, an artificial antigen against cyproheptadine(CPH) was successfully synthesized by bromoacetic acid substitution method. An ultrasensitive and broad-specific monoclonal antibody $(\mathrm{mAb})$ able to recognize $\mathrm{CPH}$ and six phenothiazines (PZs) was produced. Based on the gold-labeled mAb, an immunochromatographic strip (ICS) was established.

Results: The $50 \%$ inhibition concentration $\left(\mathrm{IC}_{50}\right)$ of the produced $\mathrm{mAb}$ against $\mathrm{CPH}$ was identified as 0.036 $\mathrm{ng} \mathrm{mL} \mathrm{mL}^{-1}$ by ELISA, and the cross-reactivities for six PZs were from $6.33 \%$ to $63.16 \%$. The visual detection limits(cut-off values) of the developed ICS ranged from 5 to $100 \mathrm{ngg}^{-1}$ in feedstuffs. Take a reading by strip reader, the $\mathrm{IC}_{50}$ was from 0.570 to $7.750 \mathrm{ng} \mathrm{g}^{-1}$. In addition, a recovery experiment was carried out to verify the reliability of the ICS. The intra-assay recoveries were from $79.83 \%$ to $103.38 \%$ with the highest coefficient of variation (CV) of $11.31 \%$. The inter-assay recoveries were from $79.00 \%$ to $96.63 \%$ with the highest CV of $12.66 \%$.

Conclusions: We have successfully produced a broad-spectrum monoclonal antibody and established an ICS for simultaneouslydetecting CPH and six PZs drugs.In brief, the proposed ICS was considered suitable for qualitatively and quantitatively monitoring $\mathrm{CPH}$ and PZs in feedstuffs.

\section{Introduction}

Cyproheptadine $(\mathrm{CPH})$, an antihistamine drug, is extensively employed to treat allergic disorders caused by histamine overproduction in humans [1, 2]. In addition, $\mathrm{CPH}$ can stimulate the appetite by inhibiting 5hydroxytryptamine activity in the hypothalamus, leading to increases in growth rate and body weight[3, 4]. $\mathrm{CPH}$ has a similar effect on animals as clenbuterol, thus it has been utilized as a feed additive. Currently, in consideration of the allergic and other potential hazards for consumers posed by $\mathrm{CPH}$ residues in animal edible tissues [5], $\mathrm{CPH}$ has been banned as a veterinary drug for food-producing animals according to EU Directive 2001/82[6]. In the announcement No. 176 and 1519 of China's Ministry of Agriculture, $\mathrm{CPH}$ was prohibited to use in feedstuffs and drinking water [7]. However, many investigations have shown illegal use or overuse of $\mathrm{CPH}$ by farmers to promote growth of animals due to its price advantage and effectiveness[6, 8]. It follows that an available test tool is urgently needed to monitor the illegal use of $\mathrm{CPH}$.

Phenothiazines (PZs) are a class of sedative and hypnotic drugs with a common structure of thioaniline rings. PZs included promethazine (PTZ), chlorpromazine (CPZ), perphenazine (PPZ), fluphenazine (FPZ), 
acepromazine (APZ) and thioridazine (TDZ) were normally used in the treatment of human psychiatric diseases. In animal husbandry, PZs are used as feed additives and are conducive to weight gain by limiting animal movement and reducing the consumption of nutrients. Meanwhile, PZs are applied as anti-stress drugs in the transportation of food producing animals [9]. However, the use of PZs in these ways can leave residues in the edible tissues of food-derived animals and thus endanger human health. It was found that $\mathrm{CPZ}$ is a potential risk for engendering adverse reactions, such as dermatological reactions, leukocytosis, obstructive and orthostatic hypotension, leukopenia and jaundice [10]. Although the toxicity of other phenothiazines remains unclear, they may have the same pathogenicity as chlorpromazine because of the common structure. Considering the potential harm of PZs to consumers, the European Union banned the use of CPZ in food animals in any form [11]. According to the announcement NO. 176 and NO. 235 of the Ministry of Agriculture of China, PZs have also been banned as feed additives and must be undetectable in edible tissues of animals[12].

Up to now, a few analytical techniques have been developed for the detection of $\mathrm{CPH}$, such as capillary electrophoresis- electrochemiluminescence assay [1], high performance liquid chromatography (HPLC) [6, 13], liquid chromatography-tandem mass spectrometry (LC-MS/MS) [8, 14, 15], gas chromatographymass spectrometry (GC-MS) [2] and so on. There are also many instrumental analytical methods for the detection of PZs in biological matrixes, including HPLC [16, 17], GC-MS [18-20], LC-MS/MS [13] and ultrahigh-performance liquid chromatography-Q-Trap tandem mass spectrometry (UPLC-MS/MS) [21]. These instrumental detection methods show the advantages of good stability and high sensitivity [22]. However, above techniques and instruments require skilled technical support, and are expensive and timeconsuming $[23,24]$. Furthermore, they are not practical for on-site detection or rapid screening of large numbers of samples $[25,26]$. A simple, rapid, reliable and low-cost method is imperatively needed to monitor illegal use and deal with high-throughput screening of $\mathrm{CPH}$ or PZs.

Immunochemical methods, especially colloidal gold immunochromatographic strips (ICS), are receiving increasing attention due to their convenient and practicality $[27,28]$. At present, many test strips have been reported on the detection of various veterinary drugs and feed additives, including aminoglycoside antibiotic [29]. sulfonamides antibacterial agents [30], vancomycin [31], paromomycin [32], polymyxin B [33] and sildenafil [34]. To the best of our knowledge, none immunochromatographic assays have been established to detect CPH or PZs. In this study, an artificial immunogen CPH-BSA was designed and prepared, then a mAb with high affinity and sensitivity was obtained. Based on the antibody, one ICS was developed to simultaneously screen for $\mathrm{CPH}$ and PZs in feedstuffs.

\section{Materials And Methods}

\section{Chemicals, reagents and apparatus}

FPZ standard was purchased from Dr. Ehrenstorfer GmbH (Augsburg, Germany). CPH and other PZs standards were purchased from Aladdin Chemistry Co., Ltd. 5-(1-methyl-4-piperidyl)-5H-dibenzo(a, d) cyclohepten-5-ol hydrochloride ( $\mathrm{COH}$ ) was bought from SHANGHAI ZZBIO Co., Ltd. Bovine serum 
albumin (BSA), ovalbumin (OVA), bromoacetic acid, 1-(3-dimethylaminopropul)-3-ethylcarbodiimide hydrochloride (EDC), N-hydroxysuccinimide (NHS), Freund's complete adjuvant (FCA), Freund's incomplete adjuvant (FIA), hypoxanthine aminopterin thymidine (HAT), hypoxanthine thymidine (HT), 2(N-morpholino) ethanesulfonic acid (MES), 3,3',5,5'-tetramethylbenzidine (TMB), gold chloride trihydrate and Tween 20 were purchased from Sigma (St. Louis, USA). Horseradish peroxidase-labelled goat antimouse IgG (HRP-anti-IgG) was bought from Sino-American Biotechnology Co. (Luoyang, China). Goat anti-mouse IgG antibody (whole molecule) was from Sino American Biotechnology Co. (Luoyang, China). PEG 1500 was bought from Roche (Mannheim, Germany). All other chemical reagents used were of analytical grade or higher. Ninety-six-well culture plates were from Nunc (Roskilde, Denmark). Nitrocellulose membranes, glass fiber and absorbent pads were purchased from Millipore (Bedford, USA).

Milli-Q Ultrapure System was from Millipore (Redford, USA). Microplate Reader 550 used here was from Bio-Rad (Richmond, USA). The XYZ Biostrip Dispenser, CM 4000 cutter and TSR3000 membrane strip reader were all from Bio-Dot (Richmond, USA).

Eight weeks old female BALB/c mice were obtained from the Laboratory Animal Center, Zhengzhou University, China. The animal experiments were performed under the guidelines $f$ Key Laboratory of Animal Immunity, Henan Academy of Agricultural Sciences and approved by the Animal Ethics Committee.

\section{Preparation of immunogen and coating antigen}

Here, the hydroxyl group-containing $\mathrm{COH}$ was introduced into the carboxyl group by substitution with bromoacetic acid, and conjugated with BSA or OVA using EDC/NHS method, the route was shown in Fig.

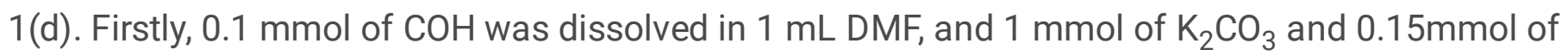
bromoacetic acid were added carefully. This substitution reaction was performed at room temperature under stir for $4 \mathrm{~h}$. The reaction solution was then centrifuged at $5000 \times g$ for $10 \mathrm{~min}$, the supernatant was carefully collected and adjusted to $\mathrm{pH} 5.0$ with $\mathrm{HCl}$. EDC $(0.15 \mathrm{mmol})$ and $\mathrm{NHS}(0.15 \mathrm{mmol})$ were added into the supernatant and react for $15 \mathrm{~min}$ at room temperature. Finally, half the volume of the solution was added dropwise to $1.5 \mathrm{~mL}$ of $0.1 \mathrm{mmol} \mathrm{L}^{-1} \mathrm{BSA}$ solution and another half to $1.5 \mathrm{~mL}$ of $0.1 \mathrm{mmol} \mathrm{L}^{-1}$ OVA solution, then incubated for $4 \mathrm{~h}$ at room temperature. The mixtures were dialyzed in PBS for $3 \mathrm{~d}$ at $4^{\circ} \mathrm{C}$.

\section{Preparation of anti-CPH mAb}

The production of anti-CPH mAb was performed as described previously [35]. Four female BALB/c mice were subcutaneously injected with $200 \mu \mathrm{L}$ of a 1:1 (v/v) mixture of PBS and FCA containing $50 \mu \mathrm{g}$ immunogen. At 21-day interval, the mice received another three further immunizations with the same dosage of immunogen but using FIA instead of FCA for the emulsification of the antigen respectively. Sera were collected on the tenth day after the fourth immunization and tested for anti-CPH activity by enzyme-linked immunosorbent assay (ELISA). The mouse with highest sensitivity and titer of anti-CPH antibodies was selected as the spleen donor. The selected mouse was immunized intraperitoneally with 
$50 \mu \mathrm{g}$ of $\mathrm{CPH}-\mathrm{BSA}$ in PBS, then three days later the spleen cells were used for fusion with myeloma cells using PEG1500 [36]. The supernatant of the hybridoma cells was tested by ELISA. The hybridoma cells that secreted high anti-CPH activity antibodies were subcloned by limiting dilution. To obtain large numbers of monoclonal antibodies against $\mathrm{CPH}$, the BALB/c mice received an intraperitoneal injection of the selected hybridoma (0.5-1.0 × $10^{6}$ cells for each mouse). The ascites fluid was collected after ten says and purified by caprylic acid and ammonium sulfate method (CA-SA).

\section{Competitive ELISA}

The development of the indirect competitive ELISA (ic-ELISA) was performed according to conventional protocols [37]. The optimum coating antigen and mAb concentrations for competitive ELISA were determined by the bi-dimensional titration assay. The indirect competitive ELISA (ic-ELISA) process was as follows. First, a series of standard solutions were added to the reaction plate with $100 \mu \mathrm{L}$ per well, and the mAb solution was added expect blank wells. The plate was incubated at $37^{\circ} \mathrm{C}$ for $15 \mathrm{~min}$ and then washed with PBST (PBS containing $0.05 \%$ Tween 20) four times. Second, $100 \mu \mathrm{L}$ of HRP-anti-lgG was added per well and the plate was incubated at $37^{\circ} \mathrm{C}$ for $30 \mathrm{~min}$. After washing step, $100 \mu \mathrm{L}$ of the TMB dilution buffer was added per well, then the plate was incubated at $37^{\circ} \mathrm{C}$ for $15 \mathrm{~min}$. Finally, the reaction was terminated with $50 \mu \mathrm{L}$ of $2 \mathrm{~mol} \mathrm{~L}^{-1} \mathrm{H}_{2} \mathrm{SO}_{4}$ per well, and the optical density (OD) values at $450 \mathrm{~nm}$ were read by a microplate reader. Furthermore, the standard curve was constructed from the ratio of measured OD values to negative values against logarithmic concentrations. The concentrations of halfmaximal inhibition $\left(\mathrm{IC}_{50}\right)$ and the limit of detection $\left(\mathrm{LOD}, \mathrm{IC}_{10}\right)$ were computed from the regression equation. To evaluate the specificity of the $\mathrm{mAb}$, the $\mathrm{IC}_{50}$ values of binding of the $\mathrm{mAb}$ with other compounds were measured. The cross-reaction was determined by the following formula:

Cross-reactivity $(\%)=\left(\mathrm{IC}_{50}\right.$ against $\left.\mathrm{CPH}\right) /\left(\mathrm{IC}_{50}\right.$ against the other compound $) \times 100 \%$

\section{Preparation of colloidal gold- mAb probe and ICS}

Colloidal gold was prepared as previously described with average particle diameter of approximately 24 $\mathrm{nm}$ [38]. The nanoparticles were conjugated with $\mathrm{mAb}$ as reported with slight modification [39]. Concisely, the $\mathrm{pH}$ of the colloidal gold solution $\left(10 \mathrm{~mL}\right.$ ) was adjusted to 8.2 with $0.2 \mathrm{M} \mathrm{K}_{2} \mathrm{CO}_{3}$, then $1 \mathrm{~mL}$ of $\mathrm{mAb}$ solution $\left(150 \mu \mathrm{g} \mathrm{mL}^{-1}\right)$ was added dropwise under gently stirring. After reaction at room temperature for $30 \mathrm{~min}, 2 \mathrm{~mL}$ of $10 \%$ BSA was added to block excess gold nanoparticles, and reacted for a further $15 \mathrm{~min}$ at room temperature. The mixed solution was centrifuged at $12000 \times \mathrm{g}$ for 30 min under $4^{\circ} \mathrm{C}$. The supernatant was cautiously removed and $2 \mathrm{~mL}$ of the gold pellets were resuspended in borate buffer $(\mathrm{pH}$ 9.0). The conjugate solution was stored at $4^{\circ} \mathrm{C}$ for use.

The assembly of ICS was shown in Fig. 2. The strip consisted of a semirigid polyethylene sheet (backing card), a nitrocellulose (NC) membrane, a sample pad, a conjugate pad and an absorbent pad.[38] The NC membrane $(20 \mathrm{~mm} \times 30 \mathrm{~mm}$ ) was spotted with one test line ( $\mathrm{T}$ line) applied with CPH-BSA and one control line ( $\mathrm{C}$ line) with goat anti-mouse $\mathrm{IgG}$, with $0.5 \mathrm{~cm}$ between the two lines. The conjugate pad was 
treated with colloidal gold- mAb solution. The sample pad was saturated with TB solution (0.01M PBS containing $1 \% \mathrm{BSA}, 1 \%$ sucrose and $0.05 \%$ Tween 20 ). The assembled card was cut into $3 \mathrm{~mm}$ wide strips, then sealed and stored under dry condition.

\section{Test procedure and principle}

The competitive immunoassay theory was applied to this ICS, shown in Fig. 2. Briefly, $100 \mu \mathrm{L}$ of sample solution was dripped onto the sample pad, which flowed all the way through the NC membrane to the absorbent pad by capillary action. In the absence of an analyte in the sample, gold-labelled mAb gradually released as the solution flowed could bind to the capture antigen to form antibody-antigen complexes and are intercepted on the $T$ line. This line appeared bright red. Conversely, when enough dose of analyte existed in the sample, the analyte would block the gold-labelled antibodies and avoided their coupling with the capture antigen, the $T$ line was colorless. The lower dose of analyte in a sample, the more obvious $\mathrm{T}$ line. The $\mathrm{C}$ line was always visible red regardless whether the sample contained analyte or not. Otherwise, the strip should be discarded and a new strip used.

\section{Analysis of feedstuff samples using ICS}

The samples of swine feedstuffs were provided by Henan Academy of Agricultural Sciences. The sample preparation followed the previous method with slight modification [6, 40]. In short, $10 \mathrm{~g}$ of feed was weighed into a $50 \mathrm{~mL}$ centrifuged tube, and vortexed for 2 min after adding into $25 \mathrm{~mL}$ methanol. The extraction solution was then sonicated in a water bath for $15 \mathrm{~min}$, then centrifuged at $10000 \times g$ for 10 min. The methanol supernatant was collected and the solvent evaporated under a gentle stream of nitrogen. Finally, the dried leftover was resuspended in $10 \mathrm{~mL}$ of PBS (containing $10 \%$ methanol). The standard solution of each drug was prepared with methanol at a concentration of $1 \mathrm{mg} \mathrm{mL}^{-1}$ and diluted with feedstuff extracts. The final concentrations of CPH in treated sample were $0,0.156,0.313,0.625$, $1.25,2.5$ and $5 \mathrm{ng} \mathrm{g}^{-1}$, the concentrations of PTZ were $0,1.953,3.906,7.813,15.625,31.25$ and $62.5 \mathrm{ng} \mathrm{g}^{-}$ 1 , those of CPZ were $0,0.391,0.782,1.563,3.125,6.25$ and $12.5 \mathrm{ng} \mathrm{g}^{-1}$, those of PPZ were $0,1.563,3.125$, $6.25,12.5,25$ and $50 \mathrm{ng} \mathrm{g}^{-1}$, those of APZ were $0,1.563,3.125,6.25,12.5,25$ and $50 \mathrm{ng} \mathrm{g}^{-1}$, those of TDZ were $0,0.625,1.25,2.5,5,10$ and $20 \mathrm{ng} \mathrm{g}^{-1}$, those of FPZ were $0,3.125,6.25,12.5,25,50$ and $100 \mathrm{ng} \mathrm{g}^{-1}$.

\section{Results And Discussion}

\section{Characterization of immunogen}

$\mathrm{CPH}$ is not immunogenic due to its small molecular weight. To produce highly sensitive antibodies, $\mathrm{CPH}$ must be efficiently conjugated with the carrier protein. BSA is the most commonly used carrier protein because it is cost-effective. The structures of $\mathrm{CPH}$ and $\mathrm{COH}$ were shown in Fig. 1(a) and Fig. 1(b), $\mathrm{CPH}$ has no active group for coupling and $\mathrm{COH}$ has a free hydroxyl group, therefore, $\mathrm{COH}$ was selected for structure modification. Bromoacetic acid substitution is a feasible method with high reaction efficiency and mild reaction process. In our study, a carboxyl group was introduced to $\mathrm{COH}$ by substituting the 
hydroxyl group, then carboxylated $\mathrm{COH}$ was connected to the free amino group of BSA by EDC/NHS. Afterwards, the conjugated reactant was qualitatively analyzed by UV spectrophotometry. As shown in Fig. 1(c), the maximum absorption peaks of carrier protein BSA and CPH were at $280 \mathrm{~nm}$ and $285 \mathrm{~nm}$, respectively. However, the immunogen CPH-BSA had a shifted peak at between 280 and $285 \mathrm{~nm}$. Accordingly, the synthesis of the immunogen was considered successful.

\section{Characterization of the mAb}

After a series of screening, a target cell line (10D3-C3) was obtained. The mAb of 10D3-C3 was produced and purified by the conventional CA-SA. The properties of the mAb were determined by ELISA. The affinity constant (Ka) of 10D3-C3 was estimated as $7.353 \times 10^{9} \mathrm{~L} \mathrm{~mol}^{-1}$. The titer of the mAb was as high as $1: 1.102 \times 10^{6}$ and the mAb belonged to IgG2a sub-class. As shown in Table 1, the $\mathrm{IC}_{50}$ value was calculated from the inhibition standard curve of $\mathrm{CPH}$ or PZs by ic-ELISA, ranged from 0.036 to $0.569 \mathrm{ng} \mathrm{g}^{-}$ 1. Additionally, there was little cross-reaction between $\mathrm{CPH}$ and other analogues including diclazuril (DIC), benzimidazole (BMD) and diclofenac sodium (DFS). The cross-reaction (CR) rates were less than $1 \times 10^{-6}$, indicated that 10D3-C3 possessed satisfactory specificity. The ultra-sensitive mAb was the vital basis for developing ICS.

\section{Optimization and analytical characteristics of the ICS}

According to previous reports [34], the parameters affecting the performances of ICS are mainly $\mathrm{pH}$, the concentrations of gold-labeled mAb and capture antigen. The color depth of $\mathrm{T}$ line is the evaluation standard for parameter optimization. After a series of color comparisons, the optimal $\mathrm{pH}$ range was from 7 to 8.5 , thus the readily available PBS was chosen as the sample re-suspension. The optimal concentrations of capture antigen and mAb were determined to $0.15 \mathrm{mg} \mathrm{mL}^{-1}$ and $12.5 \mathrm{\mu g} \mathrm{mL}^{-1}$.

To assess the sensitivity of the ICS, a series of analyte standard were diluted with processed sample solution and tested by the strips. As shown in Fig. 4, with increasing concentration of analyte standard, there was a change in the color of $\mathrm{T}$ line from dark to light as observed by the naked eye. Moreover, the cut-off value was obtained at the lowest concentration of analyte, where the $T$ line was colorless. As shown in Fig. 4 and Table 2, the cut-off values of the ICS for CPH and PZs were from 5 to $100 \mathrm{ng} \mathrm{g}^{-1}$. The $\mathrm{G} / \mathrm{D} \times \mathrm{A}$ (area) of the relative optical density (ROD) and G/peak values of $\mathrm{T}$ lines were measured by BioDot TSR3000 Membrane Strip Reader. The sigmoidal dose-response curves were generated by concentrations of analytes and the G/D $\times A$ (area) of the ROD. The linear equation (LE) for CPH was $y=$ $-5377 x+0.8019\left(R^{2}=0.9916\right)$, the APZ's LE was $y=-5738 x+0.8781\left(R^{2}=0.9935\right)$, the FPZ's LE was $y=$ $-5101 \mathrm{x}+0.8412\left(R^{2}=0.9979\right)$, the PPZ's LE was $\mathrm{y}=-5485 \mathrm{x}+0.8154\left(R^{2}=0.9976\right)$, the PTZ's LE was $\mathrm{y}=$ $-5521 \mathrm{x}+0.8391\left(R^{2}=0.9958\right)$, the CPZ'S LE was $\mathrm{y}=-5304 \mathrm{x}+0.7944\left(R^{2}=0.9960\right)$ and the TDZ's LE was $y=-4904 x+0.7977\left(R^{2}=0.9965\right)$. The IC 50 values were computed from the standard curves, ranged from 0.570 to $7.750 \mathrm{ng} \mathrm{g}^{-1}$, the LOD values ranged from 0.103 to $1.354 \mathrm{ng} \mathrm{g}^{-1}$. The above results showed that the established ICS was highly sensitive and sufficient for monitoring $\mathrm{CPH}$ and six PZs. 


\section{Recovery of $\mathrm{CPH}$ in feedstuff samples}

The accuracy of the ICS was evaluated by a recovery experiment. Feedstuffs containing $\mathrm{CPH}(0.4,0.8$ and $\left.1 \mathrm{ng} \mathrm{g}^{-1}\right)$, PTZ $\left(3,5\right.$ and $\left.15 \mathrm{ng} \mathrm{g}^{-1}\right)$ or TDZ $\left(1,3\right.$ and $\left.5 \mathrm{ng} \mathrm{g}^{-1}\right)$ were extracted and separately detected by the ICS. The measured G/D $\times A$ (area) of the ROD values were inserted into the standard curve equations and the sample concentration values were calculated. The results were shown in Table 3. To determine intraassay reproducibility, each sample was tested in triplicate with the same batch of strips, the recoveries ranged from $79.83 \%$ to $103.38 \%$ and the highest coefficient of variation (CV) were $11.31 \%$. To determine inter-assay reproducibility, three different batches of strips were applied to test the samples in triplicate. Recoveries were from $79.00 \%$ to $96.63 \%$ and the highest CV was $12.66 \%$. In general, recoveries between $75 \%$ and $125 \%$ and the CV below $15 \%$ were considered acceptable. Thus, the test strip exhibited satisfactory accuracy.

\section{Conclusions}

In this study, we successfully designed the artificial hapten and prepared an immunogen CPH-BSA. Subsequently, an ultrasensitive and broad-specific mAb recognizing both $\mathrm{CPH}$ and PZs was prepared. Further, an ICS device for simultaneous detection of CPH and PZs in feedstuffs was established. The overall analysis time was within $10 \mathrm{~min}$ by the naked eye and the cut-off values were from 5 to $100 \mathrm{ng} \mathrm{g}^{-}$

1. In summary, the ICS was an ideal, practical, cost-effective tool for preliminarily screening CPH and PZs chemical hazards in feedstuffs, also provided the potential to detect $\mathrm{CPH}$ and PZs in food matrixes.

\section{Abbreviations}

$\mathrm{CPH}$ : cyproheptadine; $\mathrm{COH}$ : 5-(1-methyl-4-piperidyl)-5H-dibenzo(a, d)cyclohepten-5-ol hydrochloride; PZs: phenothiazines; PTZ: promethazine; CPZ: chlorpromazine; PPZ: perphenazine; FPZ: fluphenazine; APZ: acepromazine; TDZ: thioridazine; BSA: bovine serum protein; OVA: ovalbumin; mAb: monoclonal antibody; ICS: immunochromatographic strip; NC: nitrocellulose; HPLC: high performance liquid chromatography; LC-MS: liquid chromatographic-tandem mass spectrometry; GC-MS: gas chromatography-mass spectrometry; UPLC-MS: ultra-high performance liquid chromatography-tandem mass spectrometry; ELISA: enzyme-linked immunosorbent assay; ic-ELISA: indirect competitive ELISA; DIC: diclazuril; BMD: benzimidazole; DFS: diclofenac sodium; FCA: Freund's complete adjuvant; FIA: Freund's incomplete adjuvant; EDC: 1-ethyl-carbodiimidehydrochloride; NHS: N-hydroxysuccinimide; MES: 2-(N-morpholino) ethanesulfonic acid; HAT: hypoxanthine aminopterin thymidine; HT: hypoxanthine thymidine; HRP: horseradish peroxidase; IgG: immunoglobulin; TMB: 3,3',5,5'-tetramethylbenzidine; CASA: octanoic acid-ammonium sulfate method; OD: optical density value; $\mathrm{IC}_{50}: 50 \%$ inhibition concentration; LOD: limit of detection; CR: cross-reactivity rate; PBS: phosphate buffer; PBST: PBS containing $0.05 \%$ Tween 20; ROD: relative optical density; LE: linear equation; CV: coefficient of variation

\section{Declarations}


Acknowledgements

All co-authors thank the financial support of the National Key Research and Development Program of China (2018YFC1602903).

\section{Authors' contributions}

Guanqiong Na designed the experiments and wrote the manuscript. The majority of the experiments were completed by Guanqiong $\mathrm{Na}$, Xiaofei Hu, Yaning Sun and Yunrui Xing. The development of immunoassay strip was contributed by Guanqiong NA and Yaning Sun. The manuscript revision was contributed by Xiaofei Hu, Sharon Kwee and Guangxu Xing. The fund was acquired and managed by Gaiping Zhang. All authors read and approved the final manuscript.

\section{Funding}

This research was financially supported by the National Key Research and Development Program of China (2018YFC1602903).

\section{Availability of data and materials}

All data of our study are included in this published article.

\section{Ethics approval}

Eight-week-old female BALB/c mice were supplied by the Laboratory Animal Center in Zhengzhou University, China. All animal experiments were approved by the Animal Ethics Committee and conducted under the guidelines of Key Laboratory of Animal Immunization, Henan Academy of Agricultural Sciences.

\section{Consent for publication}

Not applicable.

\section{Competing interests}

The authors declare that they have no competing interests.

\section{Author details}

${ }^{1}$ Key Laboratory for Animal Immunology of the Ministry of Agriculture, Henan Academy of Agricultural Sciences, Zhengzhou 450002, China. ${ }^{2}$ School of Food Science and Technology, Jiangnan University, Wuxi, Jiangsu 214122, China. ${ }^{3}$ Department of Biomedical Engineering, University of Texas at San Antonio, San Antonio, TX 78249, USA. ${ }^{4}$ College of Animal Science and Veterinary Medicine, Henan Agricultural University, Zhengzhou 450002, China. 


\section{References}

1. Zhu, D., L. Xia, J. Sun, and T. You. Chemometrics optimization of six antihistamines separations by capillary electrophoresis with electrochemiluminescence detection. Talanta. 2012; 88: 265-271.

2. Chika, H., K. Takeshi, L. Xiao-Pen, F. Masaya, K. Ayako, M. Akemi, et al. Simultaneous determination of ten antihistamine drugs in human plasma using pipette tip solid-phase extraction and gas chromatography/mass spectrometry. Rapid Commun Mass Spectrom. 2010; 20: 537-543.

3. Harrison, M.E., M.L. Norris, A. Robinson, W. Spettigue, M. Morrissey, and L. Isserlin. Use of cyproheptadine to stimulate appetite and body weight gain: A systematic review. Appetite. 2019; 137: 62-72.

4. Rerksuppaphol, S. and L. Rerksuppaphol. Anterior displacement of anus: a common association with constipation in infancy. Asian Biomedicine. 2010; 4: 595-601.

5. Kaur, M., P. Raj, N. Singh, A.S. Kuwar, and N. Kaur. Benzimidazole based Imine-linked Copper Complexes in Food Safety: Selective Detection of Cyproheptadine and Thiabendazole. Acs Sustainable Chemistry \& Engineering. 2018; 6 .

6. Yang, J., Z. Wang, T. Zhou, X. Song, Q. Liu, Y. Zhang, et al. Determination of cyproheptadine in feeds using molecularly imprinted solid-phase extraction coupled with HPLC. J Chromatogr B Analyt Technol Biomed Life Sci. 2015; 990: 39-44.

7. Zhang, G.J., B.H. Fang, Y.H. Liu, X.F. Wang, L.X. Xu, Y.P. Zhang, et al. Development of a multi-residue method for fast screening and confirmation of 20 prohibited veterinary drugs in feedstuffs by liquid chromatography tandem mass spectrometry. Journal of Chromatography B Analytical Technologies in the Biomedical \& Life Sciences. 2013; 936: 10-17.

8. Fente, C.A., R. Patricia, B.I. Vázquez, F. Xexús, C.M. Franco, and C. Alberto. Development and validation of an LC-MS/MS confirmatory method for residue analysis of cyproheptadine in urine of food-producing animals. Journal of Agricultural \& Food Chemistry. 2009; 57: 2595-8.

9. Amaral, L., M. Viveiros, and J. Molnar. Antimicrobial activity of phenothiazines. In Vivo. 2004; 18: 725-731.

10. Lekshmi, M., P. Ammini, S. Kumar, and M.F. Varela. The food production environment and the development of antimicrobial resistance in human pathogens of animal origin. Microorganisms. 2017; 5: 11.

11. Gao, B.L., J. Liu, L.X. Dong, L. Zhang, J.H. Qin, and J.P. Wang. Broad specific enzyme-linked immunosorbent assay for determination of residual phenothiazine drugs in swine tissues. Anal Biochem. 2014; 454: 7-13.

12. Liu, W., W. Li, W. Yin, M. Meng, Y. Wan, C. Feng, et al. Preparation of a monoclonal antibody and development of an indirect competitive ELISA for the detection of chlorpromazine residue in chicken and swine liver. Journal of the Science of Food \& Agriculture. 2010; 90: 1789-1795.

13. Maham, M., V. Kiarostami, S. Waqif-Husain, P. Abroomand-Azar, M.S. Tehrani, S.M. Khoeini, et al. Extraction and Determination of Cyproheptadine in Human Urine by DLLME-HPLC Method. Iranian 
Journal of Pharmaceutical Research. 2013; 12: 311-318.

14. Xesús, F., Y. Lei, S.V. Hosseini, C.A. Fente, and C. Alberto. Development and validation of LC-MS/MS method for the determination of cyproheptadine in several pharmaceutical syrup formulations. $J$ Pharm Biomed Anal. 2009; 50: 1044-1049.

15. Gustavo Duarte, M., A. André, C.L. Shi, K.M. Alkharfy, and D.N. Gilberto. Quantification of cyproheptadine in human plasma by high-performance liquid chromatography coupled to electrospray tandem mass spectrometry in a bioequivalence study. Biomedical Chromatography Bmc. 2015; 26: 129-136.

16. Cruz-Vera, M., R. Lucena, S. Cárdenas, and M. Valcárcel. Determination of phenothiazine derivatives in human urine by using ionic liquid-based dynamic liquid-phase microextraction coupled with liquid chromatography. Journal of Chromatography B. 2009; 877: 37-42.

17. Saracino, M.A., M. Amore, E. Baioni, C. Petio, and M.A. Raggi. Determination of selected phenothiazines in human plasma by solid-phase extraction and liquid chromatography with coulometric detection. Analytica Chimica Acta. 2008; 624: 308-316.

18. Pujadas, M., S. Pichini, E. Civit, E. Santamariña, K. Perez, and R.D.L. Torre. A simple and reliable procedure for the determination of psychoactive drugs in oral fluid by gas chromatography-mass spectrometry. Journal of Pharmaceutical \& Biomedical Analysis. 2007; 44: 594-601.

19. Kamaruzaman, S., M.M. Sanagi, N. Yahaya, and W.A. Wan Ibrahim. Magnetic micro-solid-phase extraction based on magnetite-MCM-41 with gas chromatography-mass spectrometry for the determination of antidepressant drugs in biological fluids. 2017; 40: 4222-4233.

20. Rosado, T., D. Oppolzer, B. Cruz, M. Barroso, S. Varela, V. Oliveira, et al. Development and validation of a gas chromatography/tandem mass spectrometry method for simultaneous quantitation of several antipsychotics in human plasma and oral fluid. 2018; 32: 2081-2095.

21. Yin, Z., T. Chai, P. Mu, N. Xu, Y. Song, X. Wang, et al. Multi-residue determination of 210 drugs in pork by ultra-high-performance liquid chromatography-tandem mass spectrometry. J Chromatogr A. 2016; 1463: 49-59.

22. Wang, Z., L. Guo, L. Liu, H. Kuang, and C. Xu. Colloidal gold-based immunochromatographic strip assay for the rapid detection of three natural estrogens in milk. Food Chemistry. 2018; 259.

23. Wang, Z., J. Zhang, L. Liu, X. Wu, H. Kuang, C. Xu, et al. A colorimetric paper-based sensor for toltrazuril and its metabolites in feed, chicken, and egg samples. Food Chem. 2019; 276: 707-713.

24. Guo, L., S. Song, L. Liu, J. Peng, H. Kuang, and C. Xu. Comparsion of an immunochromatographic strip with ELISA for simultaneous detection of thiamphenicol, florfenicol and chloramphenicol in food samples. Biomed Chromatogr. 2015; 29: 1432-9.

25. Guo, Y., B. Ngom, T. Le, X. Jin, L. Wang, D. Shi, et al. Utilizing three monoclonal antibodies in the development of an immunochromatographic assay for simultaneous detection of sulfamethazine, sulfadiazine, and sulfaquinoxaline residues in egg and chicken muscle. Anal Chem. 2010; 82: 75505 . 
26. Liu, Y., Y. Zhao, T. Zhang, Y. Chang, S. Wang, R. Zou, et al. Quantum Dots-Based Immunochromatographic Strip for Rapid and Sensitive Detection of Acetamiprid in Agricultural Products. Front Chem. 2019; 7: 76.

27. Chen, Y., L. Guo, L. Liu, S. Song, H. Kuang, and C. Xu. Ultrasensitive Immunochromatographic Strip for Fast Screening of 27 Sulfonamides in Honey and Pork Liver Samples Based on a Monoclonal Antibody. Journal of Agricultural \& Food Chemistry. 2017; 65: 8248-8255.

28. Peng, J., L. Liu, L. Xu, S. Song, K. Hua, C. Gang, et al. Gold nanoparticle-based paper sensor for ultrasensitive and multiple detection of 32 (fluoro)quinolones by one monoclonal antibody. Nano Research. 2017; 10: 108-120.

29. Sun, Y., J. Yang, S. Yang, Q. Sang, and G. Zhang. Development of an immunochromatographic lateral flow strip for the simultaneous detection of aminoglycoside residues in milk. Rsc Advances. 2018; 8: 9580-9586.

30. Chen, Y., L. Liu, L. Xu, S. Song, H. Kuang, G. Cui, et al. Gold immunochromatographic sensor for the rapid detection of twenty-six sulfonamides in foods. Nano Research. 2017.

31. Kong, D., Z. Xie, L. Liu, S. Song, K. Hua, and C. Xu. Development of ic-ELISA and lateral-flow immunochromatographic assay strip for the detection of vancomycin in raw milk and animal feed. Food \& Agricultural Immunology. 2017; 28: 414-426.

32. Isanga, J., D. Mukunzi, Y. Chen, S. Suryoprabowo, L. Liu, K. Hua, et al. Development of a monoclonal antibody assay and a lateral flow strip test for the detection of paromomycin residues in food matrices. Food \& Agricultural Immunology. 2017; 28: 355-373.

33. Li, Y., L. Liu, S. Song, H. Kuang, and C. Xu. A Rapid and Semi-Quantitative Gold Nanoparticles Based Strip Sensor for Polymyxin B Sulfate Residues. Nanomaterials. 2018; 8: 144.

34. Wang, Z., X. Wu, L. Liu, L. Xu, H. Kuang, and C. Xu. An immunochromatographic strip sensor for sildenafil and its analogues. Journal of Materials Chemistry B. 2019; 7: 6383-6389.

35. Song, C., Q. Liu, A. Zhi, J. Yang, Y. Zhi, Q. Li, et al. Development of a lateral flow colloidal gold immunoassay strip for the rapid detection of olaquindox residues. J Agric Food Chem. 2011; 59: 9319-9326.

36. KÖHLER, G. and C. MILSTEIN. Continuous cultures of fused cells secreting antibody of predefined specificity. Nature. 1975; 47.

37. Yaning, S., H. Xiaofei, Z. Yong, Y. Jifei, W. Fangyu, W. Yao, et al. Development of an immunochromatographic strip test for the rapid detection of zearalenone in corn. Journal of Agricultural \& Food Chemistry. 2014; 62: 11116.

38. Yao, J., Y. Sun, Q. Li, F. Wang, M. Teng, Y. Yang, et al. Colloidal gold-McAb probe-based rapid immunoassay strip for simultaneous detection of fumonisins in maize. J Sci Food Agric. 2017; 97 : 2223-2229.

39. Sun, Y., X. Hu, Y. Zhang, J. Yang, F. Wang, Y. Wang, et al. Development of an immunochromatographic strip test for the rapid detection of zearalenone in corn. Journal of Agricultural \& Food Chemistry. 2014; 62: 11116. 
40. Wang, J., Y. Wang, Y. Pan, D. Chen, Z. Liu, L. Feng, et al. Preparation of a generic monoclonal antibody and development of a highly sensitive indirect competitive ELISA for the detection of phenothiazines in animal feed. Food Chem. 2017; 221: 1004-1013.

\section{Tables}

Table 1. Cross-reactivity of the mAb identified by ELISA

\begin{tabular}{ccc}
\hline Compounds & $\mathrm{IC}_{50}\left(\mathrm{ng} \mathrm{mL} \mathrm{m}^{-1}\right)$ & Cross-reactivity (\%) \\
\hline $\mathrm{CPH}$ & 0.036 & 100.00 \\
\hline $\mathrm{PTZ}$ & 0.764 & 4.71 \\
\hline $\mathrm{CPZ}$ & 0.057 & 63.16 \\
\hline $\mathrm{PPZ}$ & 0.155 & 23.22 \\
\hline $\mathrm{FPZ}$ & 0.388 & 9.28 \\
\hline $\mathrm{APZ}$ & 0.569 & 6.33 \\
\hline $\mathrm{TDZ}$ & 0.088 & 40.91 \\
\hline $\mathrm{DIC}$ & $>10^{5}$ & $<10^{6}$ \\
\hline $\mathrm{BMD}$ & $>10^{5}$ & $<10^{6}$ \\
\hline $\mathrm{DFS}$ & $>10^{5}$ & \\
\hline
\end{tabular}

Table 2. Sensitivity of the ICS 


\begin{tabular}{|c|c|c|c|c|}
\hline Compounds & Structures & $\begin{array}{c}\text { Cut-off values } \\
\left(\mathrm{ng} \mathrm{g}^{-1}\right)\end{array}$ & $\begin{array}{c}\begin{array}{c}\text { IC50 } \\
\left(n^{2} g^{-1}\right)\end{array} \\
\end{array}$ & $\begin{array}{r}\text { LOD } \\
\left(\mathrm{ng} \mathrm{g}^{-1}\right)\end{array}$ \\
\hline $\mathrm{CPH}$ & & 5 & 0.570 & 0.103 \\
\hline PTZ & & 62.5 & 3.896 & 0.617 \\
\hline $\mathrm{CPZ}$ & & 12.5 & 0.720 & 0.119 \\
\hline PPZ & & 50 & 2.952 & 0.495 \\
\hline \multicolumn{5}{|l|}{ FPZ } \\
\hline & & 100 & 7.750 & 1.354 \\
\hline \multicolumn{5}{|l|}{$\mathrm{APZ}$} \\
\hline & & 50 & 3.562 & 0.716 \\
\hline TDZ & & 20 & 1.290 & 0.115 \\
\hline
\end{tabular}

Table 3. Recoveries and inter-assay and intra-assay precision of the immunoassay strips for CPH spiked in feedstuff 


\begin{tabular}{|c|c|c|c|c|c|c|c|}
\hline \multirow[t]{3}{*}{ Analyte } & \multirow[t]{3}{*}{ Concentration $\left(\mathrm{ng} \mathrm{g}^{-1}\right)$} & \multicolumn{3}{|c|}{ Intra-assay } & \multicolumn{3}{|c|}{ Inter-assay } \\
\hline & & Tested & Recovery (\%) & CV (\%) & Tested & Recovery (\%) & CV $(\%)$ \\
\hline & & $\left(\mathrm{ng} \mathrm{g}^{-1}\right)$ & & & $\left(\mathrm{ng} \mathrm{g}^{-1}\right)$ & & \\
\hline \multirow[t]{3}{*}{$\mathrm{CPH}$} & 0.4 & $0.368 \pm 0.022$ & 92.00 & 5.98 & $0.347 \pm 0.025$ & 86.75 & 7.20 \\
\hline & 0.8 & $0.827 \pm 0.037$ & 103.38 & 4.47 & $0.732 \pm 0.049$ & 91.50 & 6.69 \\
\hline & 1.0 & $0.803 \pm 0.046$ & 80.30 & 5.73 & $0.790 \pm 0.054$ & 79.00 & 6.84 \\
\hline \multirow[t]{3}{*}{ PTZ } & 3 & $2.395 \pm 0.109$ & 79.83 & 4.55 & $2.593 \pm 0.166$ & 86.43 & 6.40 \\
\hline & 5 & $4.172 \pm 0.343$ & 83.44 & 8.22 & $4.471 \pm 0.251$ & 89.42 & 5.61 \\
\hline & 15 & $15.207 \pm 1.579$ & 101.38 & 10.38 & $13.698 \pm 0.797$ & 91.32 & 5.82 \\
\hline \multirow[t]{3}{*}{ TDZ } & 1 & $0.799 \pm 0.057$ & 79.90 & 7.13 & $0.822 \pm 0.064$ & 82.20 & 7.79 \\
\hline & 3 & $2.803 \pm 0.0 .317$ & 93.43 & 11.31 & $2.899 \pm 0.367$ & 96.63 & 12.66 \\
\hline & 5 & $4.155 \pm 0.188$ & 83.10 & 4.52 & $4.360 \pm 0.335$ & 87.20 & 7.68 \\
\hline
\end{tabular}

Figures
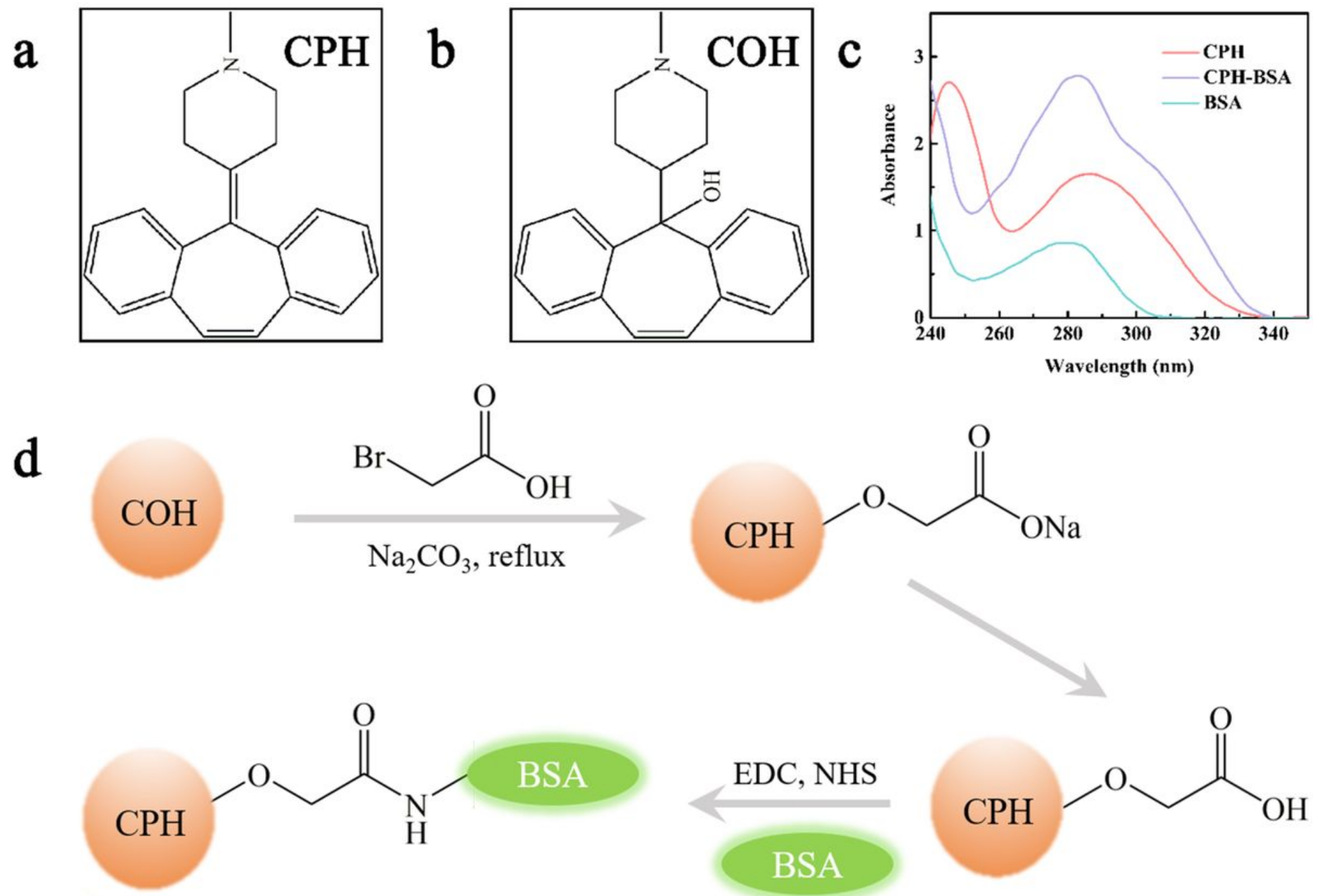
Figure 1

Chemical structures of $\mathrm{CPH}(\mathrm{a})$ and $\mathrm{COH}(\mathrm{b})$; the UV spectroscopy of $\mathrm{CPH}, \mathrm{BSA}$ and $\mathrm{CPH}-\mathrm{BSA}$ (c),the preparation of immunogen $\mathrm{CPH}-\mathrm{BSA}(\mathrm{d})$.
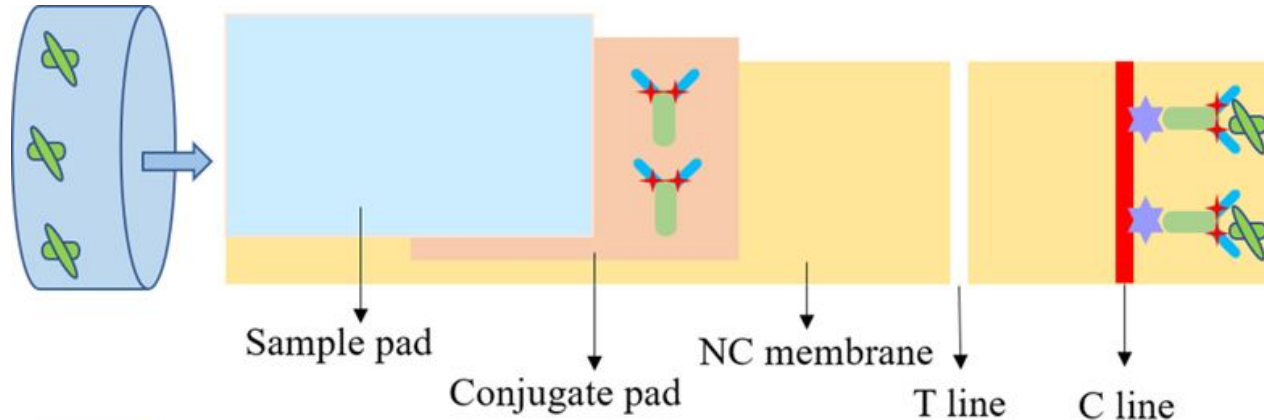

T line

C line
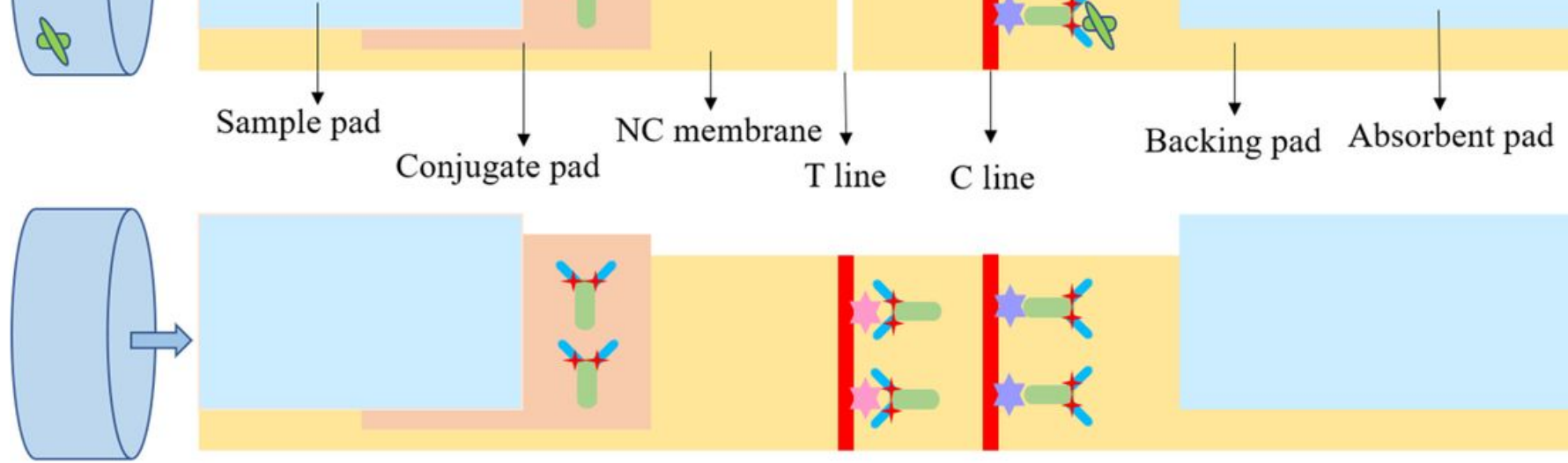

of Analyte

Coating antigen

Goat anti-mouse

Gold-mAb

\section{Figure 2}

Schematic illustration of ICS for detecting analyte. 
a

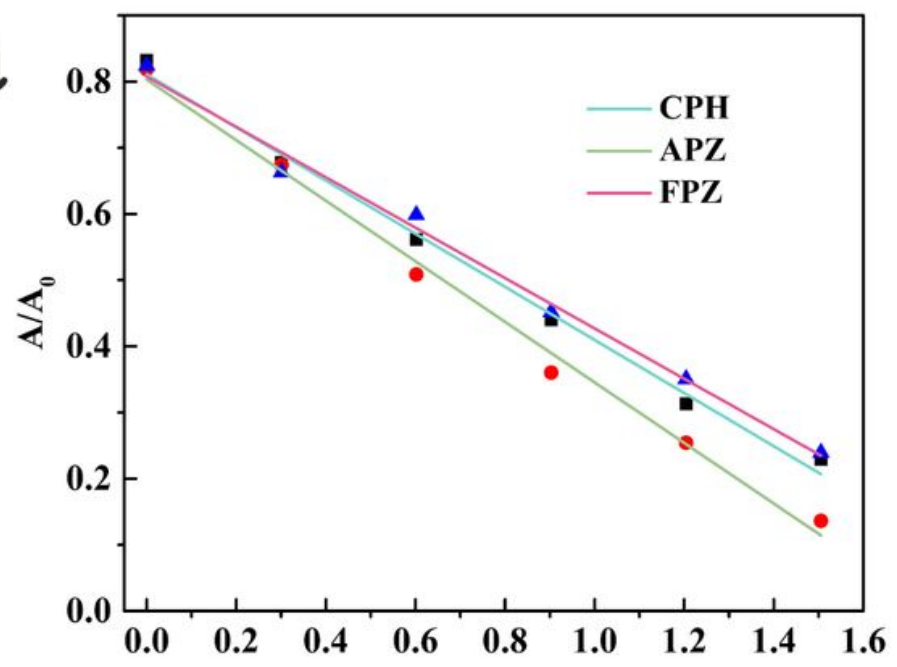

$\operatorname{Lg}\left[\right.$ concentration $\left.\left(\mathrm{ng} \mathrm{mL}^{-1}\right)\right]$

c

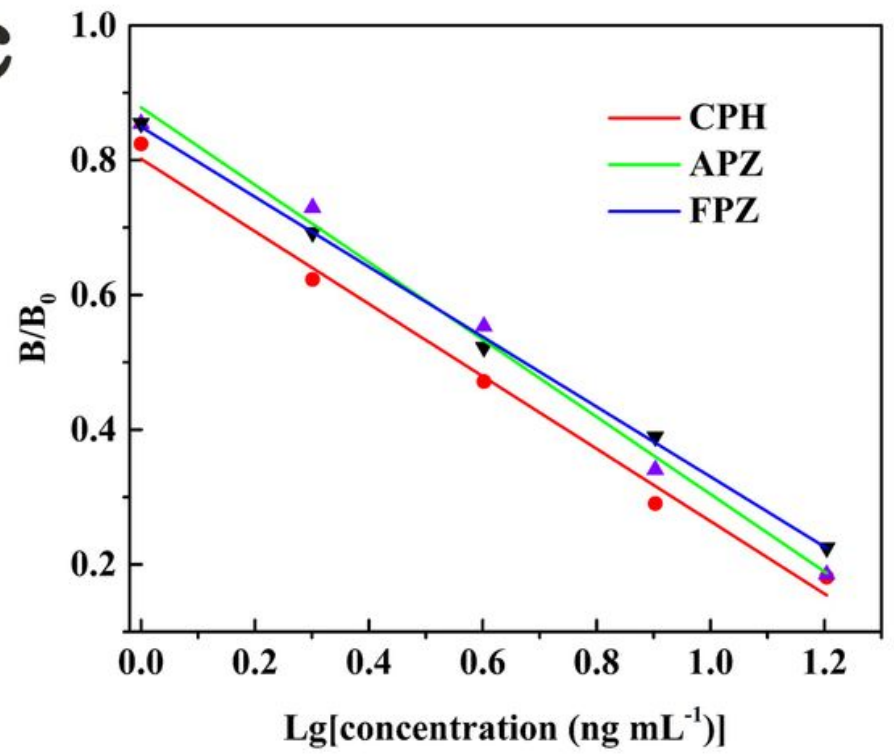

b

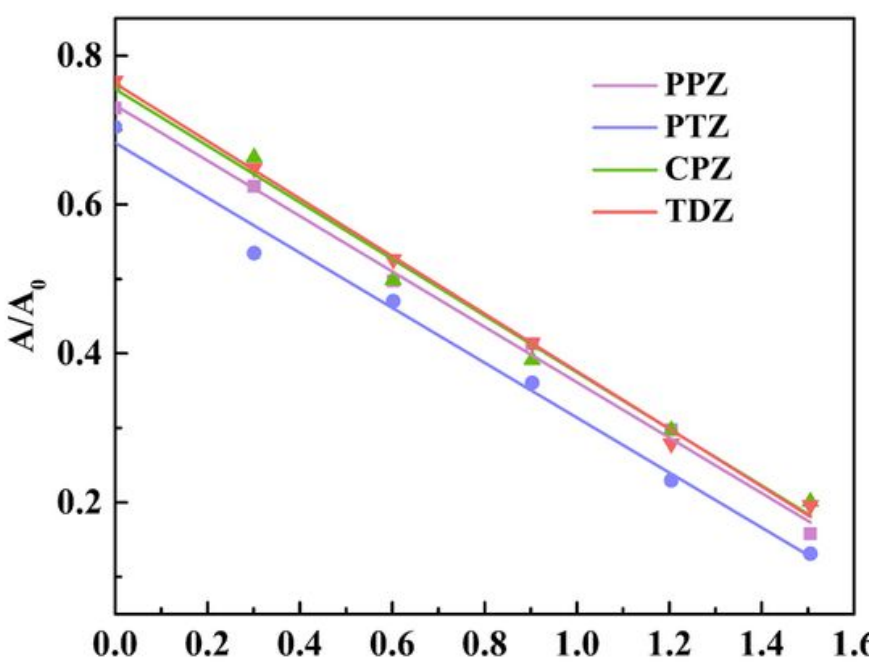

$\mathrm{Lg}\left[\right.$ concentration $\left.\left(\mathrm{ng} \mathrm{mL}^{-1}\right)\right]$

d

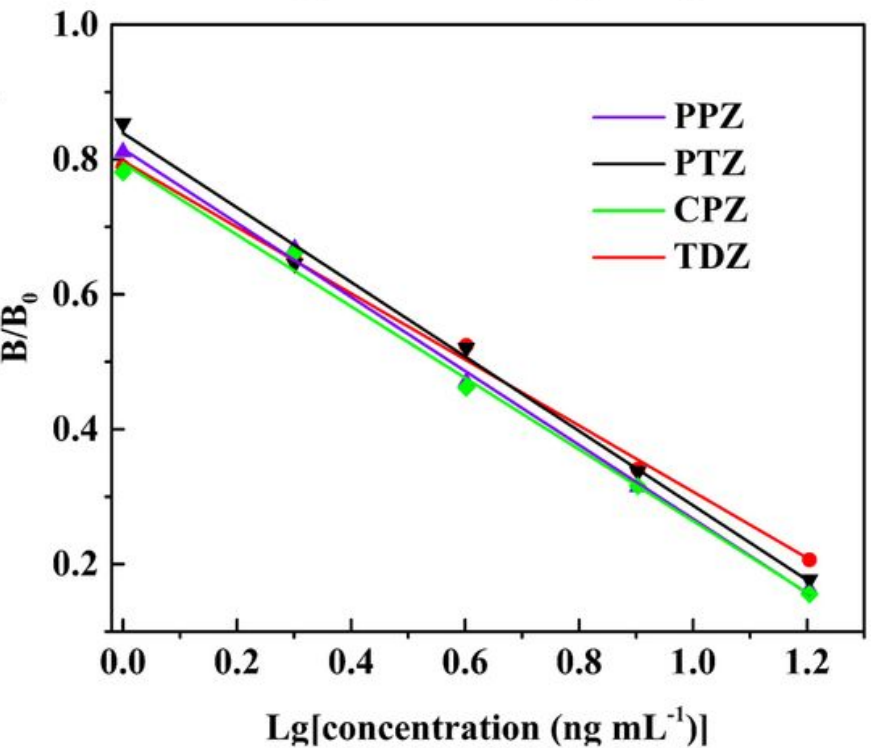

Figure 3

TheStandard curves for $\mathrm{CPH}$ and PZs in feedstuff samples evaluated with ic-ELISA (a: CPH, APZ and FPZ; b: PPZ, PTZ, CPZ and TDZ) and ICS (c: CPH, APZ and FPZ; d: PPZ, PTZ, CPZ and TDZ). 

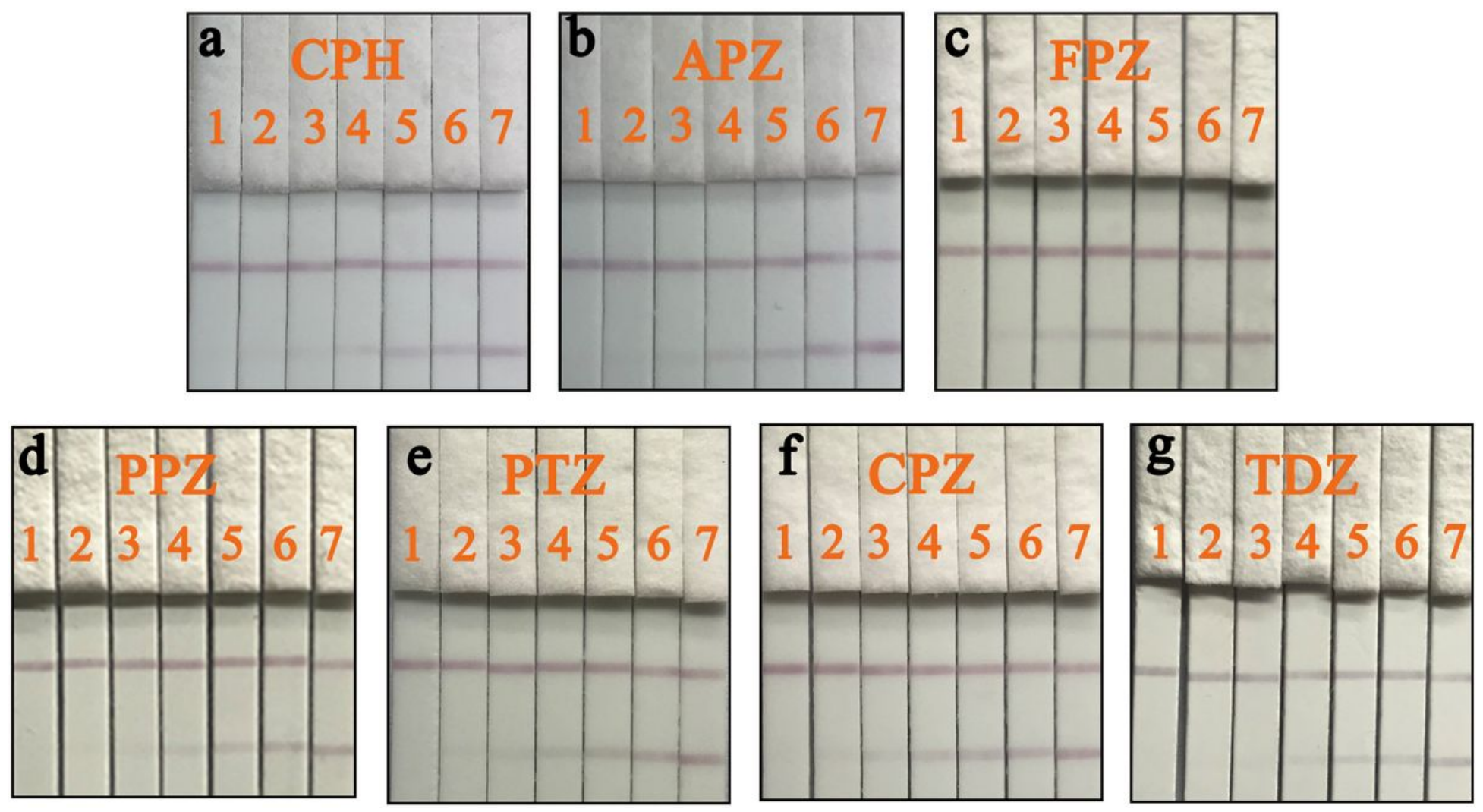

Figure 4

Concentration range of analyte spiked with feedstuff sample assayed by ICS. (a) CPH: $0,0.156,0.313$, $0.625,1.25,2.5$ and $5 \mathrm{ng}$ g-1; (b) APZ: 0, 1.563, 3.125, 6.25, 12.5, 25 and 50ng g- 1 ; (c) FPZ: 0, 3.125, 6.25, 12.5, 25, 50 and 100ng g-1; (d) PPZ: 0, 1.563, 3.125, 6.25, 12.5, 25 and 50 ng g-1; (e)PTZ: 0, 1.953, 3.906, 7.813, 15.625, 31.25 and 62.5ng g-1; (f) CPZ: 0, 0.391, 0.782, 1.563, 3.125, 6.25 and 12,5ng g-1; (g) TDZ:0, $0.625,1.25,2.5,5,10$ and $20 \mathrm{ng} \mathrm{g}-1$. 